\title{
Relationships among flash point, carbon residue, viscosity and some impurities in biodiesel after ethanolysis of rapeseed oil
}

\author{
Michal Černoch, Martin Hájek ${ }^{*}$, František Skopal
}

Department of Physical Chemistry, Faculty of Chemical Technology, University of Pardubice, Czech Republic

Corresponding author: Martin Hájek, Department of Physical Chemistry, Faculty of Chemical Technology, University of Pardubice, Studentská 573, 53210 Pardubice, Czech Republic.

Phone: +420 466037 055, Fax: +420 466037 068; e-mail: martin.hajek2@upce.cz

\begin{abstract}
Many samples of rapeseed oil ethyl ester were prepared by alkaline-catalyzed transesterification at various conditions (reaction time, temperature, amount of catalyst, the molar ratio of ethanol to oil, the rotations of a disperser and the purification by water). The concentrations of the key impurities for biodiesel quality (the concentrations of monoglycerides, diglycerides, triglycerides, free glycerol, ethanol, free fatty acids, water) and some qualitative parameters (flash point, carbon residue, kinematics viscosity at $40{ }^{\circ} \mathrm{C}$ ) were determined and then the relationships among them were found out. The relationships were characterized by the linear or non-linear statistical models. The found models enable the better understanding of the significance of the qualitative parameters and estimate them from the concentrations of impurities. The temperature
\end{abstract}


dependence was also measured in the case of the viscosity of ethyl ester and used rapeseed oil.

Keywords: biodiesel, ethyl ester, rapeseed oil, statistical evaluation, ethanolysis

\section{Introduction}

Recently, the world importance of biodiesel production has significantly increased. The decrease of carbon dioxide emissions, the independence from imported crude oil and better sales possibilities for farmers are some of the reasons of biodiesel importance. Nowadays the mixing of fatty acid methyl esters (FAME) into fossil diesel fuel is requested by laws in many countries (EU, 2009).

Biodiesel production proceeds mainly by the transesterification reaction of vegetable oil and low-molecular alcohol. Alkaline, acid or enzymatic catalysis are also possible. There is also a method without the using of a catalyst, whereas alcohol reacts in a supercritical state (Warabi et al., 2004). But alkaline catalysis is the most effective and widely used method (Meneghetti et al., 2006).

The most used alcohol is methanol, but the use of ethanol is possible, too. The use of ethanol has several advantages in the comparison with methanol. Ethanol is less toxic, can be easily produced from renewable sources and allows for the reaching of the higher theoretical weight yield of biodiesel because of the higher molecular weight of the formed esters (providing that oil is the key component). Further, ethyl ester formed by the transesterification reaction has a slightly higher heating value than analogous methyl ester (Knothe, 2008). On the other hand, ethanol is more expensive than methanol, forms an undesirable azeotropic mixture with water and has a lower reactivity in 
comparison with methanol during transesterification (Warabi et al., 2004; Issariyakul et al., 2007), which is caused by a longer carbon chain (Nimcevic et al., 2000).

This work is aimed at the investigation of relationships among some important impurities and qualitative parameters of rapeseed oil ethyl ester samples, namely the concentration of potassium ions, free glycerol, ethanol, mono-, di- and triglycerides as well as flash point, carbon residue and kinematic viscosity.

\section{Materials and methods}

\subsection{Researching strategy}

Generally, there are two ways of researching the relationships among independent and dependent variables - mechanistic or statistical. The mechanistic way is based on the knowledge and the utilization of natural laws and general dependencies. The advantages of this method are the physical principle of mechanistic model parameters and the possibility of an extrapolation outside the measured interval. On the other hand, the more complicated form of model equations is the disadvantage. The statistical method uses the simpler form of model equations that do not correspond exactly to the natural laws. For example, transesterification studies may be based on the kinetics laws (Komers et al., 2002) or the statistical linear (Černoch et al., 2010a) or non-linear models (Bautista et. al, 2009).

Since natural laws are not known, the statistical method was chosen in this study, which is focused on the relationship among the concentrations of the important impurities (glycerides, free glycerol, potassium compounds, ethanol, water, free fatty acids) and some qualitative properties of biodiesel (flash point, viscosity, carbon residue) based on ethyl esters of rapeseed oil. The database contained approximately 50 various samples of biodiesel based on ethyl esters of rapeseed oil. Simple statistical models were chosen, 
although general dependences of some studied qualitative properties exist, e.g. the Grunberg-Nissan equation of the viscosity of liquid mixtures or the estimation of the flash point based on vapour pressure data (Guo et al., 2009).

The simplest linear model (1) was used, especially in the description of the influence of several variables on some qualitative properties (dependent variable $y$, independent variables $x_{i}$, parameters $\left.a_{i}\right)$.

$y=a_{0}+a_{1} \cdot x_{1}+a_{2} \cdot x_{2}+\ldots .+a_{i} \cdot x_{i}$

The possibility of wide statistical analysis at the linear regression processes (e.g. significance of parameters, problem of collinearity - more in section 3.1) is the advantage of the utilization of simple linear models. The statistical testing according to (Meloun and Militký, 2004) was used. On the other hand, the worse fitting of measured data is the main disadvantage. In the point of one independent variable, the usage of non-linear statistical models was considered, with respect to the suitability of fitting and the simplicity of models.

In this paper, $w_{M G}, w_{D G}$ and $w_{T G}$ mean concentrations of mono- di- and triglycerides, $w_{G}$ sum of the glycerides concentration, $w_{F G}, w_{E T}$ and $w_{F F A}$ concentrations of free glycerol, ethanol and free fatty acids (all wt.\%) and $K$ concentration of potassium ions $(\mathrm{mg} / \mathrm{kg})$.

\subsection{Chemicals}

Chemicals used for the biodiesel preparation: Cold-pressed, filtered rapeseed oil, free of erucic acid (acid number $0.60 \mathrm{mg} \mathrm{KOH} \cdot \mathrm{g}^{-1}$, water content $610 \mathrm{mg} \cdot \mathrm{kg}^{-1}$, density $920 \mathrm{~kg} \cdot \mathrm{m}^{-3}$ at $25^{\circ} \mathrm{C}$, kinematic viscosity $35.0 \mathrm{~mm}^{2} / \mathrm{s}$ at $40^{\circ} \mathrm{C}$, produced by the company RPN Slatiňany), Absolute ethanol (water content 0.12 wt.\%), potassium hydroxide p. a. (purity $90 \%$ ), carbon dioxide (for food processing industry). 


\subsection{Transesterification procedure and preparation of samples}

The double-walled laboratory reactor IKA ${ }^{\circledR}$ LR 2000 (volume 2 l) was used. A toothed disc stirrer served as the main stirrer. The high-performance disperser T-25 digital ULTRA-TURRAX $^{\circledR}$ (maximal $24000 \mathrm{rpm}$ ) was installed into the reactor. The reactor was joined to a water pump and a thermostat (Hájek et al., 2009).

Transesterification reactions were carried out under various reaction conditions. $900 \mathrm{~g}$ of rapeseed oil was put into the reactor; the catalyst (0.89-1.33 wt.\% to weight of rapeseed oil) was dissolved in ethanol (molar ratio ethanol to oil 6.0:1-7.5:1) and both liquids were thermostated separately to the reaction temperature $\left(25-65^{\circ} \mathrm{C}\right)$. Then the disperser was switched on, the solution of $\mathrm{KOH}$ in ethanol was quickly added into the reactor and this time was considered as the start of the reaction. The rotations of the disperser were set to $10000-20000 \mathrm{rpm}$, the main stirrer was set to $200 \mathrm{rpm}$ during the transesterification process because of a satisfactory heat transfer (the disperser produced high amount of heat). After the chosen reaction time (1.5-2.0 hours), the reaction was stopped by neutralisation of the catalyst by gaseous $\mathrm{CO}_{2}$ dosed into a reaction mixture until the $\mathrm{pH}$ fell to a minimum value (approximately 5 minutes). Potassium carbonate and potassium bicarbonate were formed from the $\mathrm{KOH}$; they have a negligible catalytic effect in this system (Skopal et al., 2001). Then the excess of ethanol was removed from the reaction mixture by distillation off at high temperature $\left(80-90^{\circ} \mathrm{C}\right)$ and low pressure (by means of water pump, $3 \mathrm{kPa}$ ) for $40 \mathrm{~min}$. After cooling down to $25^{\circ} \mathrm{C}$, the reaction mixture had been separated for 24 hours to the ester phase and glycerol phase by gravitation in a separatory funnel.

Some of the ester phase samples were used in the raw state (after 24 hour sedimentation), some of them after subsequent long-term sedimentation (1 month) and 
some of them were prepared by washing the raw ester phase by de-mineralized water. The combination of various transesterification and separation conditions and the mentioned washing provided a wide variability of the composition of the ester phase samples.

\subsection{Analytical methods}

The content of monoglycerides, diglycerides and triglycerides were determined by the GC method according to EN 14105 (instrument: Shimadzu GC-2010).

The content of ethanol was determined by the column GC method (instrument: Chrom 5, Laboratory instruments Prague) based on the methanol determination described by Komers et al. (1998).

The concentration of potassium ions in the EP was determined by the flame photometry (Flame photometer 410, Sherwood) with the help of a calibration curve. The calibration solutions were prepared by the mixing of small a amount of very concentrated ethanolic $\mathrm{KOH}$ solution into the biodiesel matrix without potassium ions. The biodiesel matrix was prepared by the washing of biodiesel by an aqueous solution of citric acid. The concentration of free glycerol was determined by HPLC method (Hájek et al., 2006).

The concentration of free fatty acids was calculated from the determined acid number provided that whole acidity of the sample is caused by free fatty acids. The acid number was determined by alkalimetric titration (EN 14104).

\subsection{Measurements of qualitative properties}

The flash point was measured by the Pensky-Martens closed-cup method (EN ISO 2719). The used instrument was OB-305 (MIM Fabri, Hungary). 
The carbon residue was measured by the Conradson method (CCR - Conradson carbon residue) without the preceding distillation of samples.

The kinematic viscosity was measured by the Ubelohde's viscosimeter type.

\section{Results and discussion}

\subsection{Relationship between potassium and free glycerol content}

Previous work (Černoch et al., 2009) informs about the linear dependence between the potassium ions and free glycerol content in the ester phase. Similar findings seemed to be valid also for FAME (Hájek et al., 2009; Wang et al., 2009). With regard to different separation conditions, this dependence was confirmed. The measured data are depicted in Fig. 1. These measured data confirm the approximately linear dependence between the potassium ions and free glycerol concentration, although $R^{2}$ reaches only 0.823 . However, the value of $R^{2}$ indicates that there is a more complex situation which exists in the reaction mixture and probably other unknown parameters have effect on free glycerol and potassium ion concentrations.

The found dependence is characterized by the absence of the constant term, i.e. it predicts zero concentration of free glycerol if concentration of potassium ions is also zero (almost zero concentration of both impurities was characteristic for washed samples of ester samples). The fact can be explained as the stabilisation effect of potassium soaps on the low-concentrated emulsion of glycerol in the ester phase, which is illustrated in (Wang et al., 2009). In the case of this work, potassium ions can be present in the form of potassium soaps, carbonate or hydrogen carbonate. Although determining the distribution of potassium ions among these forms in the glycerol phase is possible (Kwiecien et al., 2009), analogous determination is not feasible in the point of the ester phase because of very low potassium ions concentration. 
The previously mentioned dependence caused the collinearity problem at some of the subsequent regressions analyses because potassium ions and free glycerol contents are considered as the independent variables affecting the qualitative properties discussed in the following sections.

\subsection{Relationship among mono-, di- and triglycerides content}

The relationships among the concentration of monoglycerides (MG), diglycerides (DG) and triglycerides (TG) in the studied samples of biodiesel were investigated, too. The range of measured data is stated in Table 1 . The concentrations of MG and DG are comparable and reach approximately 0.2 to $3.8 \mathrm{wt} . \%$, whereas the concentrations of TG were significantly lower ( 0 to 1.1 wt.\%). The relationships between them, which are approximately linear at measured interval, are depicted in Fig. 2. The concentration of MG is mostly higher than the concentration of DG when the concentration of TG is lower than 0.2 wt.\% and vice versa. The washing of samples has practically no effect on the glycerides concentration.

There are two fundamental factors which influence these relationships. Firstly, the concentrations of glycerides in the whole reaction mixture are conjugated by kinetic equations, which are stated in many publications, e.g. (Komers et al., 2002) and (Bambase et al., 2007). Secondly, glycerides are distributed between the ester phase and the glycerol phase after the transesterification reaction (Černoch et al., 2010b). Unfortunately, found relationships caused problems of the next regression analyses, as it was mentioned at the end of section 3.1. Therefore, the concentrations of MG, DG and TG were summarized into one variable (the concentration of glycerides).

\subsection{Flash point}


In the case of biodiesel, the flash point (FP) decreases with increasing amounts of residual alcohol and other low-boiling solvents (Mittelbach and Remschmidt, 2004). In the case of this paper, only residual ethanol can be present in biodiesel. Therefore, the flash point was presupposed to be depending only on the ethanol content. The experimental data and their fitting by a logarithmic function are presented in Fig. 3. The flash point of ethanol-free ethyl ester of rapeseed oil reaches up approximately $195^{\circ} \mathrm{C}$. Other types of vegetable oils used for biodiesel production result in various flash points - examples are stated in (Demirbas, 2008), the prediction on the basis of the vegetable oil composition in (Yuan et al., 2009). It is also necessary to keep in mind, that various test methods of the flash point can give significantly various results. Based on Fig. 2, the concentration of ethanol over $0.2 \mathrm{wt} . \%$ decreases the flash point of biodiesel below $100^{\circ} \mathrm{C}$. Values of the flash point in the whole interval of the mixture ethanol + biodiesel are presented in (Guo et al., 2009).The largest flash point decrease is in the interval 0-10 wt.\% of ethanol in biodiesel; exceeding $10 \mathrm{wt} \%$ causes that the flash point values are practically constant and close to the flash point of pure ethanol $\left(12.8^{\circ} \mathrm{C}\right)$.

\subsection{Carbon residue}

The carbon residue is one of the most important biodiesel quality criteria (Mittelbach and Remschmidt, 2004). Generally, several methods and modifications of carbon residue determination exist. EN 14214 requires modification with a preceding distillation (EN ISO 10370) and determination of the carbon residue in the $10 \%$ of distillation residue because of the detection limit decrease and the possibility of the direct comparison with fossil diesel fuels. However, this distillation step causes problems (Mittelbach and Remschmidt, 2004; Komers and Machek, 1995). In the case 
of this work, determination of the carbon residue of the original biodiesel by the Conradson closed-cup method (CCR) without the preceding distillation was used. Thus, the measured values correspond directly with the US biodiesel norm (ASTM D6751, maximal permitted value 0.05 wt.\%) and with the EU norm (EN 14214, maximal permitted value $0.30 \mathrm{wt} . \%$ of $10 \%$ residue after distillation) after a multiplication by 10 . The CCR value of the used pure rapeseed oil reached up to 0.233 wt.\%. The interval of CCR values of biodiesel samples is stated in Table 1 . It is greatly wide $(0.003-0.320$ wt.\%) and includes several extreme values (up to $1.05 \mathrm{wt} \%$ ) that cannot be used in regression and evaluation analyses (outliers). Washed samples were characterized by the lowest CCR values. Two simplifying suppositions were used: excluding of free glycerol concentration effect (collinearity problem, section 3.1) and summation of mono-, di- and triglycerides effect to one variable (sum of glycerides) because of an analogous problem (section 3.2). The linear regression analysis according to equation (1) indicates that the concentrations of glycerides, ethanol, water and free fatty acids are insignificant variables and only the concentration of potassium ions is significant. Such a linear model of the relationship between CCR and potassium ion concentration is depicted in Fig. 4. Although the $R^{2}$ value is smaller than 0.9 , the linear dependence is evident at the investigated interval. The dependence is characterized by the absence of the constant term.

Mittelbach (Mittelbach and Remschmidt, 2004; Mittelbach and Enzelsberger, 1999) mentioned other substances (beyond potassium compounds), which increase carbon residue: glycerides, free fatty acids, polyunsaturated esters and polymers. In the case of this work, the linear regression analysis indicates the insignificant effect of glycerides and free fatty acids. This is probably caused by the investigated concentration intervals 
- glycerides and free fatty acids significantly influence the carbon residue only at higher concentrations. Fernando's work (Fernando et al., 2007) shows that the carbon residue significantly increases when concentrations of residual triglycerides reached up to approximately $10 \mathrm{wt} \% \%$ (in this work samples below $7 \mathrm{wt} \% \%$ of all glycerides). Polyunsaturated esters and polymers are characteristic in the case of used frying oils (Mittelbach and Enzelsberger, 1999; Cvengroš and Cvengrošová, 2004) and would not be significantly present in the "fresh" rapeseed oil.

The absence of the constant term in the linear dependence CCR vs. potassium ions indicates that the carbon residue of purified biodiesel is negligible. For example, the purification of various types of biodiesel by the molecular evaporator with a wiped film decreases the carbon residue virtually to zero (Cvengroš et al., 2006).

\subsection{Kinematic viscosity}

The range of measured data of the kinematic viscosity at $40^{\circ} \mathrm{C}$ is stated in Table 1 . The values reached mostly from 4.54 to $5.56 \mathrm{~mm}^{2} / \mathrm{s}$.

In the case of the viscosity, all investigated impurities can influence the kinematic viscosity of the ester phase. The known Grunberg-Nissan equation supposes a very complicated dependence including logarithmic functions and interaction parameters. A simple linear model with the insignificant influence of potassium ion content and the summation of glycerides concentration was used for the reason of the collinearity (sections 3.1 and 3.2). The result of regression analysis is shown by the equation (2):

$v_{40^{\circ} \mathrm{C}}=4.55+11.1 \cdot w_{G}+58.9 \cdot w_{F F A}-21.4 \cdot w_{E T}+33.4 \cdot w_{F G} \quad R^{2}=0.952$

The resulting model shows a significant increasing influence of glycerides, free glycerol and free fatty acids and a decreasing influence of ethanol. Thus, the viscosity of biodiesel is increased expectedly because of impurities with a higher viscosity and vice 
versa. On the contrary, the water content is evaluated as insignificant. The value of $R^{2}$ and the regression analysis indicate the suitability of the used linear model at the investigated concentration intervals. The viscosity may be used not only as the indicator of impurities in biodiesel, but also as the control parameter of the transesterification process (Ellis et al., 2008).

The constant term $4.55 \mathrm{~mm}^{2} / \mathrm{s}$ determines the viscosity of the pure ester phase. This value is exactly valid only in the case of the used rapeseed oil because it depends on the given oil or fats (C-chain length, number of double bonds). The isomeric form of the given bonded fatty acid is another important factor (Knothe and Steidley, 2007). Demirbas (2008) presented the viscosity comparison among biodiesel based on methyl ester of various vegetable oils at $40{ }^{\circ} \mathrm{C}$, whereas Allen et al. (1999) designed the model for predicting the viscosity on the basis of methyl esters composition. Ethyl ester of certain oil has a slightly higher viscosity than analogous methyl ester (Knothe and Steidley, 2007). Besides the previously mentioned composition dependencies, the viscosity has relationships with other qualitative parameters (Demirbas, 2008). The temperature dependence of the viscosity is a most important factor. Fig. 5 shows the temperature dependence in the cases of the used rapeseed oil and ethyl ester from this oil.

The measured data were fitted excellently by the modified Andrade equation (3) used for biodiesel fuel by Tat and Van Gerpen (1999) and Tate et al. (2006).

$$
\ln (v)=A+\frac{B}{T}+\frac{C}{T^{2}}
$$

The factual values of parameters (A, B, C) are stated in Fig. 5 (kinematic viscosity: $\mathrm{mm}^{2} / \mathrm{s}$, thermodynamic temperature: Kelvin). The presented temperature dependences are exactly valid only in the case of the used rapeseed oil. 


\section{Conclusions}

The relationships among the concentrations of potassium ions, free glycerol, among mono-, di- and triglycerides in biodiesel based on ethylester of rapeseed oil were evaluated by the linear regression. The flash point depends on the residual ethanol content - the dependence was expressed by a function containing a logarithmic term. Potassium content was the significant factor influencing the value of the Conradson carbon residue of biodiesel. The dependence of the kinematic viscosity on free glycerol, free fatty acids, glycerides and ethanol content was described. The temperature dependence of the kinematic viscosity was excellently fitted by a modified Andrade's equation.

\section{Acknowledgement}

This work has been funded by the research project MSM 0021627502 of the Czech Ministry of Education, Youth and Sport.

\section{References}

Allen, C.A.W., Watts, K.C., Ackman, R.G., Pegg, M.J., 1999. Predicting the viscosity of biodiesel fuels from their fatty acid ester composition. Fuel. 78, 1319-1326.

Bambase Jr., M.E., Nakamura, N., Tanaka, J., Matsumura, M., 2007. Kinetics of hydroxide-catalyzed methanolysis of crude sunflower oil for the production of fuelgrade methyl esters. J. Chem. Technol. Biotechnol. 82, 273-280.

Bautista, L.F., Vicente, G., Rodríguez, R., Pacheco, M., 2009. Optimisation of FAME production from waste cooking oil for biodiesel use. Biomass Bioenergy. 33, 862-872. 
Cvengroš, J., Cvengrošová, Z., 2004. Used frying oils and fats and their utilization in the production of methyl esters of higher fatty acids. Biomass Bioenergy. 27, 173-181. Cvengroš, J., Paligová, J., Cvengrošová, Z., 2006. Properties of alkyl esters base on castor oil. Eur. J. Lipid Sci. Technol. 108, 629-635.

Černoch, M., Skopal, F., Hájek, M., 2009. Separation of reaction mixture after ethanolysis of rapeseed oil. Eur. J. Lipid Sci. Technol. 111, 663-668.

Černoch, M.,Hájek, M., Skopal, F., 2010a. Study of effects of some reaction conditions on ethanolysis of rapeseed oil with dispergation. Bioresour. Technol. 101, 1213-1219. Černoch, M.,Hájek, M., Skopal, F., 2010b. Ethanolysis of rapeseed oil - Distribution of ethyl esters, glycerides and glycerol between ester and glycerol phases. Bioresour.

Technol. 101, 2071-2075.

Demirbas, A., 2008. Relationships derived from physical properties of vegetable oil and biodiesel fuels. Fuel. 87, 1743-1748.

Ellis, N., Guan, F., Chen, T., Poon, C., 2008. Monitoring biodiesel production (transesterification) using in situ viscometer. Chem. Eng. J. 138, 200-206.

Encinar, J.M., González, J.F., Rodríguez-Reinares, A., 2007. Ethanolysis of used frying oil. Biodiesel preparation and characterization. Fuel Process. Technol. 88, 513-522. EU, 2009. Directive 2009/28/EC of the European parliament and of the Council. Official J. Eur. Union. 52, 16-62.

Fernando, S., Karra, P., Hernandez, R., Jhaa, S.K., 2007. Effect of incompletely converted soybean oil on biodiesel quality. Energy. 32, 844-851.

Guo, Y., Wei, H., Yang, F., Li, D., Fang, W., Lin, R., 2009. Study on volatility and flash point of the pseudo-binary mixtures of sunflowerseed-based biodiesel + ethanol. J. Hazard. Mater. 167, 625-629. 
Hájek, M., Skopal, F., Machek, J., 2006. Determination of Free Glycerol in Biodiesel. Eur. J. Lipid Sci. Technol. 108, 666-669.

Hájek, M., Skopal, F., 2009. Relationship of variables affecting separation following transesterification of vegetable oil. Eur. J. Lipid Sci. Technol. 111, 499-504.

Hájek, M., Skopal, F., Kwiecien, J., 2009. Biodiesel preparation in a batch emulsification reactor. Eur. J. Lipid Sci. Technol. 111, 979-984.

Issariyakul, T., Kulkarni, M.G., Dalai, A.K., Bakhshi, N.N., 2007. Production of biodiesel from waste fryer grease using mixed methanol/ethanol system. Fuel Process. Technol. 88, 429-436.

Knothe, G., Steidley, K.R., 2007. Kinematic viscosity of biodiesel components (fatty acid alkyl esters) and related compounds at low temperatures. Fuel. 86, 2560-2567. Knothe G., 2008. “Designer” biodiesel: optimizing fatty ester composition to improve fuel properties. Energy Fuels. 22, 1358-1364.

Komers, K., Machek, J., 1995. Remarks to conradson carbonisation index and to neutralisation number of biodiesel. Proceedings of the International Conference on Standards and Analysis of Biodiesel., Vienna, 182-184.

Komers, K., Stloukal, R., Machek, J., Skopal, F., Komersová, A., 1998. Biodiesel fuel from rapeseed oil, methanol, and $\mathrm{KOH}$. Analytical methods in research and production. Eur. J. Lipid Sci. Technol. 100, 507-512.

Komers, K., Skopal, F., Stloukal, R., Machek, J., 2002. Kinetics and mechanism of the $\mathrm{KOH}$ - catalyzed methanolysis of rapeseed oil for biodiesel production. Eur. J. Lipid Sci. Technol. 104, 728-737.

Kwiecien, J., Hájek, M., Skopal, F., 2009. The effect of the acidity of rapeseed oil on its transesterification. Bioresour. Technol. 100, 5555-5559. 
Meloun, M., Militký, J., 2004 Statistické zpracování experimentálních dat. Academia, Prague.

Meneghetti, S.M.P., Meneghetti, M.R., Wolf, C.R., Silva, E.C., Lima, G.E.S., Coimbra, M.A., Soletti, J.I., Carvalho, S.H.V, 2006. Ethanolysis of castor oil and cottonseed oil: A systematic study using classical catalysts. J. Am. Chem. Soc. 83, 819822.

Mittelbach, M., Enzelsberger, H., 1999. Transesterification of heated rapeseed oil for extending diesel fuel. J. Am. Oil Chem. Soc. 76, 545-550.

Mittelbach, M., Remschmidt, C., 2004. Biodiesel, the Comprehensive Handbook, 1st ed. Martin Mittelbach, Graz.

Nimcevic, D., Puntigam, R., Worgetter, M., Gapes, R., 2000. Preparation of rapeseed oil esters of lower aliphatic alcohols. J. Am. Chem. Soc. 77, 275-280.

Skopal, F., Komers, K., Machek, J., Koropecký, I., 2001. Způsob výroby bionafty z rostlinných olejů, zejména z řepkového oleje. Czech patent CZ 289417.

Tat, M.E., Van Gerpen, J.H., 1999. The kinematic viscosity of biodiesel and its blends with diesel fuel. J. Am. Oil Chem. Soc. 76, 1511-1513.

Tate, R.E., Watts, K.C., Allen, C.A.W, Wilkie, K.I., 2006. The viscosities of three biodiesel fuels at temperatures up to $300{ }^{\circ} \mathrm{C}$. Fuel. 85, 1010-1015.

Wang, Y., Wang, X., Liu, Y., Ou, S., Tan, Y., Tang, S., 2009. Refining of biodiesel by ceramic membrane separation. Fuel Process. Technol. 90, 422-427.

Warabi, Y., Kusdiana, D., Saka, S., 2004. Reactivity of triglycerides and fatty acids of rapeseed oil in supercritical alcohols. Bioresour. Technol. 91, 283-287.

Yuan. H., Yang, B., Yang, J., 2009. Predicting Properties of biodiesel fuels using mixture topological index. J. Am. Oil Chem. Soc. 86, 375-382. 
Figure captions:

Figure 1.: Relationship between potassium ions $(K)$ and free glycerol $\left(w_{F G}\right)$ content in biodiesel based on ethyl ester of rapeseed oil

Figure 2.: Dependence of monoglycerides and diglycerides concentrations ( $\left.w_{M G}, w_{D G}\right)$ on triglycerides $\left(w_{T G}\right)$ concentration in biodiesel based on ethyl ester of rapeseed oil

Figure 3.: Measured data and fitting function of dependence of flash point (FP, measured by Pensky-Martens closed-cup method EN ISO 2719) vs. ethanol ( $\left.w_{E T}\right)$ content in biodiesel based on ethyl ester of rapeseed oil

Figure 4.: Relationship between Conradson carbon residue (CCR, without preceding distillation) and potassium ions content $(K)$ in biodiesel based on ethyl ester of rapeseed oil

Figure 5.: Temperature dependence of kinematic viscosity of biodiesel based on ethyl ester of rapeseed oil (left axis, symbol:匹 ) and used rapeseed oil (right axis, symbol: $\boldsymbol{\Lambda}$ ) 